\title{
Association of Nevirapine Levels with Rash or Hepatotoxicity Among HIV- Infected Thai Women
}

\author{
Winai Ratanasuwan ${ }^{1}$, Tavatchai Jariyasethpong ${ }^{2}$, Thanomsak Anekthananon ${ }^{1}$, Poj Intalapaporn ${ }^{2}$, \\ Supornchai Kongpatanakul ${ }^{3}$, Piyapat Pongnarin ${ }^{3}$, Punneeporn Wasinrapee ${ }^{4}$, \\ Nartlada Chantharojwong ${ }^{4}$, Boonyos Raengsakulrach ${ }^{4}$, Philip J. Peters ${ }^{5}$, \\ Janet McNicholl ${ }^{6}$, Michelle S. McConnell ${ }^{4,6}$ and Paul J. Weidle ${ }^{*, 5}$ \\ ${ }^{I}$ Department of Preventive and Social Medicine, Siriraj Hospital, Mahidol University, Bangkok, Thailand \\ ${ }^{2}$ Infectious Disease Unit, Rajavithi Hospital, Bangkok, Thailand \\ ${ }^{3}$ Department of Pharmacology, Faculty of Medicine Siriraj Hospital, Mahidol University, Bangkok, Thailand \\ ${ }^{4}$ Thailand Ministry of Public Health -US Centers for Disease Control and Prevention (CDC) Collaboration, Nonthaburi, \\ Thailand \\ ${ }^{5}$ Division of HIV/AIDS Prevention, CDC, Atlanta, GA, USA \\ ${ }^{6}$ Division of Global HIV/AIDS, CDC, Atlanta, USA
}

\begin{abstract}
Background: We performed a nested case-control study of Thai women prescribed nevirapine-based antiretroviral therapy (ART) to determine if development of rash or hepatotoxicity during the first 24 weeks of treatment is associated with plasma nevirapine concentrations.

Method: From May 2005-January 2007, we enrolled 217 women initiating nevirapine-based ART in Thailand. Cases ( $\mathrm{n}=$ 54) were women who during the first 24 weeks of treatment with nevirapine developed rash (any grade, $\mathrm{n}=42$ ) or hepatotoxicity ( $\geq$ grade $2, n=22$, [10 had both]). Controls were the next enrolled woman who was confirmed not to meet the case definition during the first 24 weeks. Nevirapine concentrations after the two week lead-in dose of $200 \mathrm{mg}$ once daily were compared between cases and controls by Wilcoxon rank-sum tests.

Results: We found no difference in Week 2 pre-dose nevirapine concentrations: cases median $=3,528 \mathrm{ng} / \mathrm{mL}(\mathrm{n}=24)$, controls median $=3,150 \mathrm{ng} / \mathrm{mL}(\mathrm{n}=30), \mathrm{p}=0.5$. Cases had higher post-dose nevirapine concentrations (median $=6,150$ $\mathrm{ng} / \mathrm{mL}, \mathrm{n}=21$ ) than controls (median $=4,746 \mathrm{ng} / \mathrm{mL}, \mathrm{n}=20, \mathrm{p}=0.02$ ). When limited to cases who developed a rash at Week 2, we found no differences in the pre-dose (median $=3,270 \mathrm{ng} / \mathrm{mL}, \mathrm{n}=12, \mathrm{p}=0.9$ ) or post-dose nevirapine concentration (median $=5,443 \mathrm{ng} / \mathrm{mL}, \mathrm{n}=9, \mathrm{p}=0.4$ ) compared with controls.

Conclusions: We cannot conclude definitively that nevirapine concentrations at two weeks of therapy are associated with rash or hepatotoxicity. It is unlikely that therapeutic drug monitoring at that time will improve identification of patients at risk for rash or hepatotoxicity.
\end{abstract}

Keywords: Adverse effect, antiretroviral, hepatotoxicity, nevirapine, rash, Thailand.

\section{INTRODUCTION}

An estimated $7-15 \%$ of patients receiving nevirapine experience drug rash or toxicity, although higher rates have been reported in Thai populations $[1,2]$. One possible explanation is that Thai patients may have higher plasma concentrations of nevirapine than North American or European patients when treated with the same dosage. The TREAT Asia cohort has found that a significant proportion of drug discontinuations (23\%) are attributed to nevirapine-

*Address correspondence to this author at the Division of HIV/AIDS Prevention, Centers for Disease Control and Prevention, 1600 Clifton Rd, MS E-45, Atlanta, GA 30329, USA; Tel: 1-404-639-6155;

E-mail:pweidle@cdc.gov induced rashes [2]. These drug discontinuations have programmatic implications for national treatment programs since nevirapine is part of the first-line regimen in many countries.

The original dosing regimen of nevirapine was developed in western countries in the 1990s and consists of a standard lead-in dose of $200 \mathrm{mg}$ once daily for the first two weeks of therapy followed thereafter by $200 \mathrm{mg}$ twice daily. This lower lead-in dose is given to minimize the risk of adverse reactions to nevirapine observed in pre-clinical trials $[3,4]$. Aftera two-week dosing period, auto-induction of hepatic P450 isoenzymes results inan approximate two-fold increase in nevirapine clearance [5]. 
The usual target trough $\left(\mathrm{C}_{\min }\right)$ plasma concentration for nevirapine considered necessary for optimal virologic response is $>3,000 \mathrm{ng} / \mathrm{mL}$ [6]. The association of nevirapine concentrations and toxicity is still under debate. One study in Amsterdam found a significant association between the development of rash and nevirapine concentrations greater than 5,300 ng/mL [7]. A study in Spain found an association between increased liver transaminases and nevirapine trough concentrations greater than $6,000 \mathrm{ng} / \mathrm{mL}$ [8]. A study in Italy, however, did not find an association between nevirapine concentrations and hepatotoxicity [9]. The multicountry "2NN Study" which included patients from Thailand, South Africa, South America, and other Western countries examined the pharmacokinetics of nevirapine and the relation to adverse events $[10,11]$. For patients receiving the standard dose of nevirapine $200 \mathrm{mg}$ twice daily, the average $C_{\max }$ was $7,030 \mathrm{ng} / \mathrm{mL}$ and $C_{\min }$ was $4,950 \mathrm{ng} / \mathrm{mL}$ across the entire cohort. The investigators found that patients from Thailand had 22\% lower clearance of nevirapine than patients from South America or Western countries. They reported no association between rash, or other adverse events, and nevirapine concentrations [10]. Another study conducted in Thailand found the mean nevirapine concentration in patients taking nevirapine-based ART drawn on average approximately 9 hours after a dose to be $8,720 \mathrm{ng} / \mathrm{mL}$ [12]; this value was higher than the $\mathrm{C}_{\max }$ reported in the 2NN Study from multiple countries [10]. The average concentrations drawn between $0-9.9$ hours was $9,900 \mathrm{ng} / \mathrm{mL}$ and between $10-14$ hours after a dose (indicative of trough concentrations) was 7,960 ng/mL [10].

The NNRTI Response study was a multi-site observational study conducted in Thailand, Zambia, and Kenya [13]. This nested case-control sub-study from the Thailand portion of the study was undertaken to determine if plasma nevirapine concentrations were associated with the development of rash or hepatotoxicity during the first 24 weeks of nevirapine-based ART.

\section{METHODS}

\section{Definition of Cases and Controls}

A total of 217 HIV-infected women were enrolled in Bangkok, Thailand at two sites - Siriraj Hospital and Rajvithi Hospital [13]. At enrollment and at weeks 2, 4, 8, 16, and 24, participants had serum alanine transaminase (ALT) and aspartate transaminase (AST) measured and were evaluated clinically for signs and symptoms of hepatitis and rash. We graded adverse events including hepatotoxicity and rash according to the National Institutes of Health's Division of AIDS guidelines as previously reported $[14,15]$.

Cases in this analysis were women who during the first 24 weeks of treatment with nevirapine-based HAART developed 1) any grade of rash or 2) an increase of at least one grade from baseline in ALT or AST to at least grade 2. Only rash or increase in ALT or AST that the study team determined to be "possibly", "probably", or "definitely" related to nevirapine, considering character and timing of the reaction, was considered. Controls were selected as the next enrolled participant at the same study site who was confirmed not to have met the case definition during the first 24 weeks of treatment.
Clinical care was provided by physicians with expertise in HIV disease at each of the study hospitals. The study protocol did not direct individual treatment decisions and the clinicians used their discretion to continue nevirapine through a mild reaction, to interrupt nevirapine therapy and restart it, or to change therapy substituting either efavirenz or a protease inhibitor for nevirapine.

\section{Specimens and Bioanalytical Methods}

Blood specimens were collected in Becton Dickinson Vacutainer ${ }^{\circledR}$ tubes containing ethylenediaminetetraacetic acid as an anticoagulant and were stored at room temperature until transported on ice to the laboratory. Plasma was separated and frozen within six hours of blood collection. The time and date of specimen collection was recorded by study nurses. CD4 cell counts were measured as previously described [13]. We tested for hepatitis B surface antigen and for hepatitis C antibody with Murex Enzyme Immunoassays (Abbott Diagnostics, Dartford, UK). Stored plasma specimens collected at 2, 4, and 8 weeks of the study were assayed for nevirapine, stavudine, and lamivudine concentration.

Stavudine, lamivudine, and nevirapine concentrations in plasma specimens were determined using an LC-MS/MS method [High Performance Liquid Chromatography (HPLC, Acquity ${ }^{\mathrm{TM}}$ Ultra Performance LC, Waters Co., Ltd. USA), Mass Spectrometer (Quattro Premier XE, Micromass Technologies, UK) and Masslynx v 4.1 software (Micromass Technologies, UK)]. The method had been developed and validated by the Department of Pharmacology, Faculty of Medicine Siriraj Hospital, Mahidol University (Bangkok, Thailand) according to the US FDA Guidance for Industry: Bioanalytical Method Validation (2001). The validation demonstrated that the method was reliable and reproducible for the intended use with respect to selectivity, sensitivity, linearity, accuracy, precision, and stability of the drugs in plasma. The assay had a linearity range of 1-8,000, 1-12,500, and $1-25,000 \mathrm{ng} / \mathrm{mL}$ for stavudine, lamivudine, and nevirapine, respectively.

\section{Assignment of Pre- and Post-Dose Nevirapine Concentrations}

Participants took versions of locally produced medications as either a fixed-dose combination of stavudine (30 or $40 \mathrm{mg}$ ), lamivudine $(150 \mathrm{mg})$, and nevirapine (200 $\mathrm{mg}$ ) [GPO-vir, Government Pharmaceutical Organization (GPO), Bangkok, Thailand] or as individual formulations of stavudine (30 or $40 \mathrm{mg}$ ) and lamivudine $(150 \mathrm{mg})$ (GPO, Bangkok, Thailand). To accommodate the need for a twoweek lead-in phase of nevirapine $200 \mathrm{mg}$ daily, women took GPO-vir once daily in the morning and stavudine and lamivudine as individual products in the evening. After two weeks, women took GPO-vir twice daily. Adherence support and counseling was provided by the clinical staff and study nurses who met with each participant at each study visit to record adherence to medications and to provide additional counseling. Upon enrolling in the study, participants were instructed to choose a time of day for ingestion of antiretroviral drugs that would best meet their needs.

Although the time when antiretroviral medications were generally given (e.g., 9 AM and 9 PM) was known, the precise time of the most recent dose of medications was not 
recorded. We relied on the concentrations of stavudine and lamivudine (while not considering the corresponding nevirapine concentrations) to determine if a plasma specimen was classified as pre-dose or post-dose. Stavudine and lamivudine are both renally cleared with plasma half-lives of $\sim 1$ hour [16] and $\sim 5-7$ hours [17], respectively. There is substantial fluctuation in the plasma concentrations of stavudine and lamivudine over a 12-hour dosing interval. The typical peak and trough stavudine concentrations following twice daily doses of 30 or $40 \mathrm{mg}$ are $>600 \mathrm{ng} / \mathrm{mL}$ (range $\sim 600-1,200$ ) and $<25 \mathrm{ng} / \mathrm{mL}$ (range, undetectable $<200)$ [18-21], respectively. The same values for lamivudine following twice daily doses of $150 \mathrm{mg}$ are $>1000 \mathrm{ng} / \mathrm{mL}$ (range $\sim 500-2,000$ ) and $<200$ (range, $\sim 50-500$ ) [22-24], respectively. In contrast, there is relatively little fluctuation in plasma nevirapine concentrations over a 12-hour dosing. Nevirapine is metabolized by hepatic cytochrome $\mathrm{P} 450$ isoenzymes, primarily CYP3A4, and auto-induces its own metabolism so that the terminal half-life decreases from $\sim 45$ hours after the first dose to $\sim 25-30$ hours following multiple dosing [25].

Considering these pharmacokinetic data, we characterized pre-dose specimens as those that had concentrations of: 1) stavudine $\leq 200 \mathrm{ng} / \mathrm{mL}$ and lamivudine $\leq 500 \mathrm{ng} / \mathrm{mL}$, or 2) stavudine $\leq 25 \mathrm{ng} / \mathrm{mL}$ and lamivudine $<650 \mathrm{ng} / \mathrm{mL}$. The latter was chosen to accommodate specimens with very low stavudine concentrations and relatively low lamivudine concentrations in order to include more data points in the pre-dose group. Post-dose specimens had concentrations of stavudine $>200 \mathrm{ng} / \mathrm{mL}$ and lamivudine $>500 \mathrm{ng} / \mathrm{mL}$. Specimens that did not meet either of these definitions were censored from the analyses.

\section{Statistical Analysis}

We calculated standard summary statistics of the enrollment characteristics including counts, proportions, medians, and quartile ranges. Nonparametric Wilcoxon rank-sum tests were used to compare the medians of selected baseline variables between cases and controls. Chi-square or Fisher's exact tests were used to compare categorical covariates. For comparisons of nevirapine concentrations between two groups of participants, we used Wilcoxon rank-sum tests. Women had at most one nevirapine concentration determined for analysis (either pre-dose or post-dose) at each of week 2, 4, or 8. Our primary comparison was of the plasma nevirapine concentrations at week 2 , where all but one woman had a specimen available. Adverse effects present at week 2 or week 4 that resulted in substitution of another drug for nevirapine confounded statistical comparisons at week 4 and week 8 (i.e., nevirapine had been discontinued before the week 4 and week 8 visit for these women), thus we did not make statistical comparisons using those data. We present the raw values for concentrations at weeks 4 and 8 for visual inspection. We also tested for differences in nevirapine concentrations according to participants' use of fluconazole and serum hepatitis B surface antigen status. We plotted nevirapine concentrations versus body-mass index and calculated Pearson's correlation coefficient to determine if there was a linear relationship. All of these statistical calculations were performed using SAS software, version 9.2 (SAS Institute, Inc., Cary, North Carolina).
Written informed consent to participate in this study was obtained from each participant according to the protocol approved by the Ethical Review Committee for Research in Human Subjects of Thailand Ministry of Public Health (Rajvithi Hospital) and the Institutional Review Boards of the Siriraj Hospital and of the CDC.

\section{RESULTS}

We identified 54 cases and selected 54 controls (Table 1), which included 34 cases and 34 controls from among 115 women enrolled at Rajvithi Hospital and 20 cases and 20 controls from among 102 women enrolled at Siriraj Hospital ( $p=0.26$ Chi-square test for proportion of cases by site). Among the 54 cases, 42 (78\%) women had rash and 22 (41\%) had hepatotoxicity; 10 (19\%) women had both rash and hepatotoxicity. The rash was first noted at week 2 for 25 women, at week 4 for eight women, at week 8 for seven women, and at week 16 for two women. Hepatotoxicity was first noted at week 2 for eight women, at week 4 for 11 women, at week 8 for one woman, and at week 16 for two women. There were 270 samples assayed for lamivudine, stavudine, and nevirapine. We assayed samples from all 54 controls at weeks 2, 4, and 8 and from cases at week 2 for 53 women (one woman had no sample available), at week 4 for 35 women (19 had discontinued nevirapine), and at week 8 for 20 women (34 had discontinued nevirapine). Based on the stavudine and lamivudine concentrations, we classified $136(50 \%)$ samples as pre-dose, $108(40 \%)$ samples as postdose, and $26(10 \%)$ as samples unclassifiable or censored. Median pre-dose concentrations were: stavudine $8 \mathrm{ng} / \mathrm{mL}$ (interquartile range [IQR], below level of quantification 22), lamivudine $191 \mathrm{ng} / \mathrm{mL}$ (IQR, 141 - 293), and nevirapine 4,377 ng/mL (IQR, 3,190 - 6,234). Median post-dose concentrations were: stavudine $643 \mathrm{ng} / \mathrm{mL}$ (IQR, 448 - 914), lamivudine $2,038 \mathrm{ng} / \mathrm{mL}$ (IQR, 1,458 - 2,878), and nevirapine $6,671 \mathrm{ng} / \mathrm{mL}$ (IQR, 5,059 - 8,934). The median post-dose nevirapine concentration was higher than the predose nevirapine concentration at week $2(\mathrm{p}<0.001)$, week 4 $(\mathrm{p}<0.01)$, and week $8(\mathrm{p}=0.02)$ indicating the assignment of pre-dose and post-dose based on the concentrations of stavudine and lamivudine was valid (Fig. 1).

\section{Nevirapine Concentrations in Cases and Controls}

We found no difference in pre-dose plasma nevirapine concentrations at week 2 comparing cases $(3,528 \mathrm{ng} / \mathrm{mL}, \mathrm{n}=$ 24) with controls $(3,150, \mathrm{n}=30, \mathrm{p}=0.5)$ (Fig. 1). Post-dose nevirapine concentrations were higher for cases who developed rash at any time (median $=6,150 \mathrm{ng} / \mathrm{mL}, \mathrm{n}=21$ ) versus controls (median $=4,746 \mathrm{ng} / \mathrm{mL}, \mathrm{n}=20, \mathrm{p}=0.02$ ); however, when limited to cases who developed a rash at week 2, we observed no differences in either pre-dose or post-dose week 2 plasma nevirapine concentrations: median $3,270 \mathrm{ng} / \mathrm{mL}(\mathrm{n}=12, \mathrm{p}=0.9)$ and median $5,443 \mathrm{ng} / \mathrm{mL}(\mathrm{n}=$ $9, \mathrm{p}=0.4)$, compared with the same controls, respectively. When limiting the analysis to only women who had hepatotoxicity, we found that they had similar pre-dose and post-dose plasma nevirapine concentrations at week 2 compared with controls. Women who developed both rash and hepatotoxicity likewise had similar pre-dose and postdose nevirapine concentrations compared with controls at week 2 . 
Table 1. Characteristics at Enrollment of Women who Developed Rash or Hepatotoxicity During the First 24 Weeks of Nevirapine-Based Antiretroviral Treatment (Cases) and Selected Controls, Bangkok, Thailand, 2005-2007

\begin{tabular}{|c|c|c|c|c|}
\hline \multicolumn{2}{|c|}{ Enrollment Characteristic } & \multirow{2}{*}{$\frac{\text { Cases }(\mathbf{n}=\mathbf{5 4})}{31(23-50)}$} & \multirow{2}{*}{$\frac{\text { Controls }(\mathbf{n}=\mathbf{5 4})}{31(24-55)}$} & \multirow{2}{*}{$\frac{\text { p-Value }}{0.8}$} \\
\hline Age (years) & Median (range) & & & \\
\hline Body Mass Index $\left(\mathrm{kg} / \mathrm{m}^{2}\right)$ & Median (range) & $21.0(12.6-29.3)$ & $21.1(13.3-37.9)$ & 0.4 \\
\hline \multicolumn{5}{|l|}{ World Health Organization Stage } \\
\hline \multirow{3}{*}{$\begin{array}{l}\text { Stage } 1 \\
\text { Stage } 2 \text { - Mild } \\
\text { Stage } 3 \text { - Moderate } \\
\text { Stage } 4 \text { - Severe }\end{array}$} & $\mathbf{N}$ & 19 & 15 & \\
\hline & $\mathbf{N}$ & 8 & 8 & \\
\hline & $\mathbf{N}$ & 11 & 8 & \\
\hline HIV Viral Load (copies/ml) & Median (range) & $67,558(2,059->750,000)$ & $91,427(852->750,000)$ & 0.9 \\
\hline \multicolumn{5}{|l|}{ Characteristic of Toxicity } \\
\hline Rash Grade & & & $\mathrm{n} / \mathrm{a}$ & \\
\hline $\begin{array}{l}1 \text { (mild) } \\
2 \text { (moderate) } \\
3 \text { (severe) } \\
4 \text { (life-threatening) }\end{array}$ & & $\begin{array}{c}16 \\
18 \\
5 \\
3\end{array}$ & & \\
\hline Hepatotoxicity Grade & & & $\mathrm{n} / \mathrm{a}$ & \\
\hline $\begin{array}{l}2(2.5-4.99 \times \text { ULN*) } \\
3(5.0-9.99 \times \text { ULN }) \\
4(\geq 10 \times \text { ULN })\end{array}$ & & $\begin{array}{c}11 \\
9 \\
2\end{array}$ & & \\
\hline
\end{tabular}

\section{Investigation of Other Co-Factors that Might be Associated with Nevirapine Concentrations}

Fluconazole was prescribed for 32 patients at the time of the week 2 visit, for 26 patients at week 4 , and for 23 patients at week 8 . There were no differences in pre-dose or post-dose nevirapine concentrations among patients taking fluconazole compared with patients not taking fluconazole at weeks 2,4 , or 8 . There were also no differences in pre-dose and post-dose nevirapine concentrations at weeks 2 , 4 , or 8 comparing women who were positive for hepatitis B surface antigen versus negative. There were too few women who were hepatitis $\mathrm{C}$ antibody positive to make meaningful comparisons. There was a marginally significant relationship between body-mass index and the post-dose plasma nevirapine concentration at week 2 (Pearson's $\mathrm{r}=-0.31, \mathrm{p}=$ $0.051)$, but not at week $4(\mathrm{r}=0.02, \mathrm{p}=0.90)$ or week $8(\mathrm{r}=$ $0.09, \mathrm{p}=0.64)$, and no significant relationship between body-mass index and pre-dose nevirapine concentrations at week $2(\mathrm{r}=-0.013, \mathrm{p}=0.92)$, week $4(\mathrm{r}=-0.06, \mathrm{p}=0.69)$ or week $8(\mathrm{r}=0.20, \mathrm{p}=0.25)$ (Fig. 2).

\section{Strata of Nevirapine Concentrations}

At week 2 while on nevirapine $200 \mathrm{mg}$ once daily, predose nevirapine concentrations ranged from $<3,000 \mathrm{ng} / \mathrm{mL}$ for $39 \%$ of women to $\geq 9,000 \mathrm{ng} / \mathrm{mL}$ for $2 \%$ of women. Post- dose concentrations ranged from $<3,000 \mathrm{ng} / \mathrm{mL}$ for $12 \%$ of women to $\geq 9,000 \mathrm{ng} / \mathrm{mL}$ for $15 \%$ of women (Table 2). At week 2, cases were not more likely than controls to have a pre-dose concentration $\geq 6,000 \mathrm{ng} / \mathrm{mL}$ ( $\mathrm{p}=0.78$ by Fishers exact test; sensitivity $=0.13$, specificity $=0.93$, predictive value positive $=0.60$, predictive value negative $=0.57$ ) or a post-dose nevirapine concentration $\geq 9,000 \mathrm{ng} / \mathrm{mL} \quad(\mathrm{p}=0.18$, sensitivity $=0.24$, specificity $=0.95$, predictive value positive $=0.83$, predictive value negative $=0.54)$. At weeks 4 and 8 (while on nevirapine $200 \mathrm{mg}$ twice daily), there were fewer pre-dose or post-dose nevirapine concentrations $<3,000 \mathrm{ng} / \mathrm{mL}$. Nevirapine concentrations $\geq 9,000 \mathrm{ng} / \mathrm{mL}$ were found at week 4 for $13 \%$ of pre-dose and $46 \%$ of postdose observations and at week 8 for $11 \%$ of pre-dose and $13 \%$ of post-dose concentrations.

\section{Strata of Nevirapine Concentrations and Effect on Subsequent Virologic Response}

At week 2, a pre-dose nevirapine concentration $<3,000$ $\mathrm{ng} / \mathrm{mL}$ was found for $21(39 \%)$ of 54 women and a post-dose nevirapine concentration $<3,000 \mathrm{ng} / \mathrm{mL}$ was found for 5 $(12 \%)$ of 41 women (Table 2 ). After week 2, an additional 5 women had a pre-dose $(\mathrm{n}=4)$ or post-dose $(\mathrm{n}=1)$ nevirapine concentration $<3,000 \mathrm{ng} / \mathrm{mL}$ for a total of 31 women who ever had a measured nevirapine concentration below the usual targeted threshold considered optimal for 


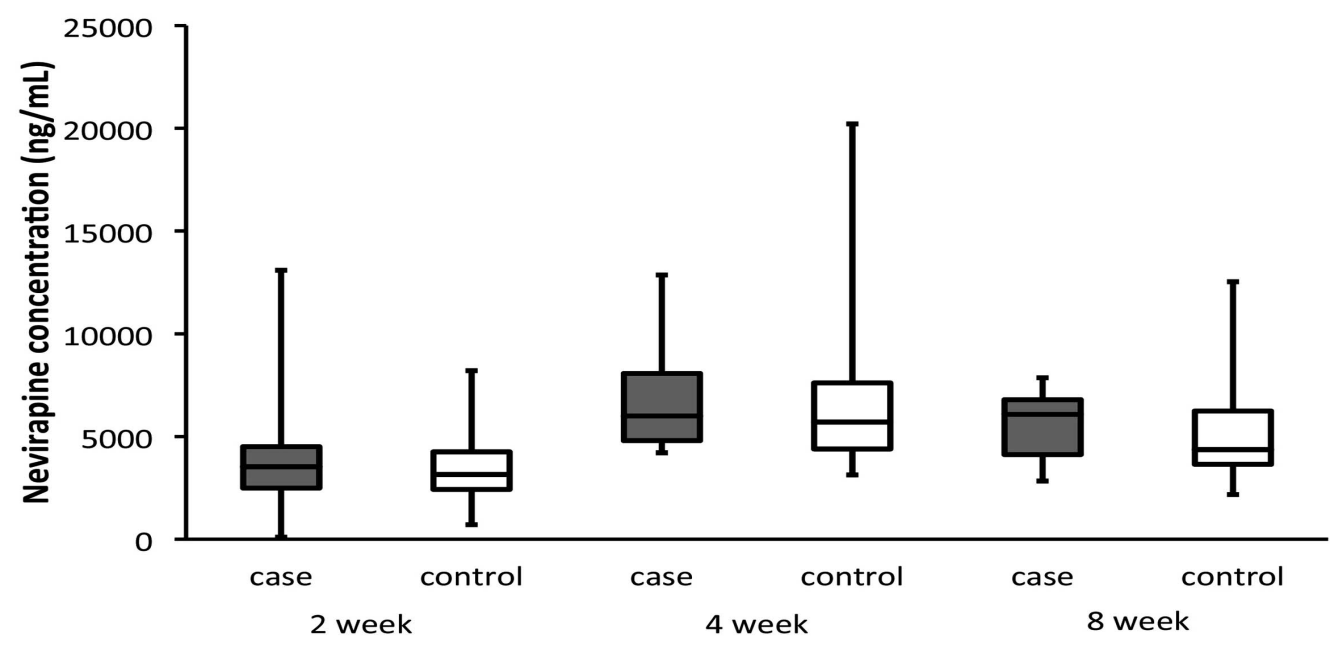

Visit week

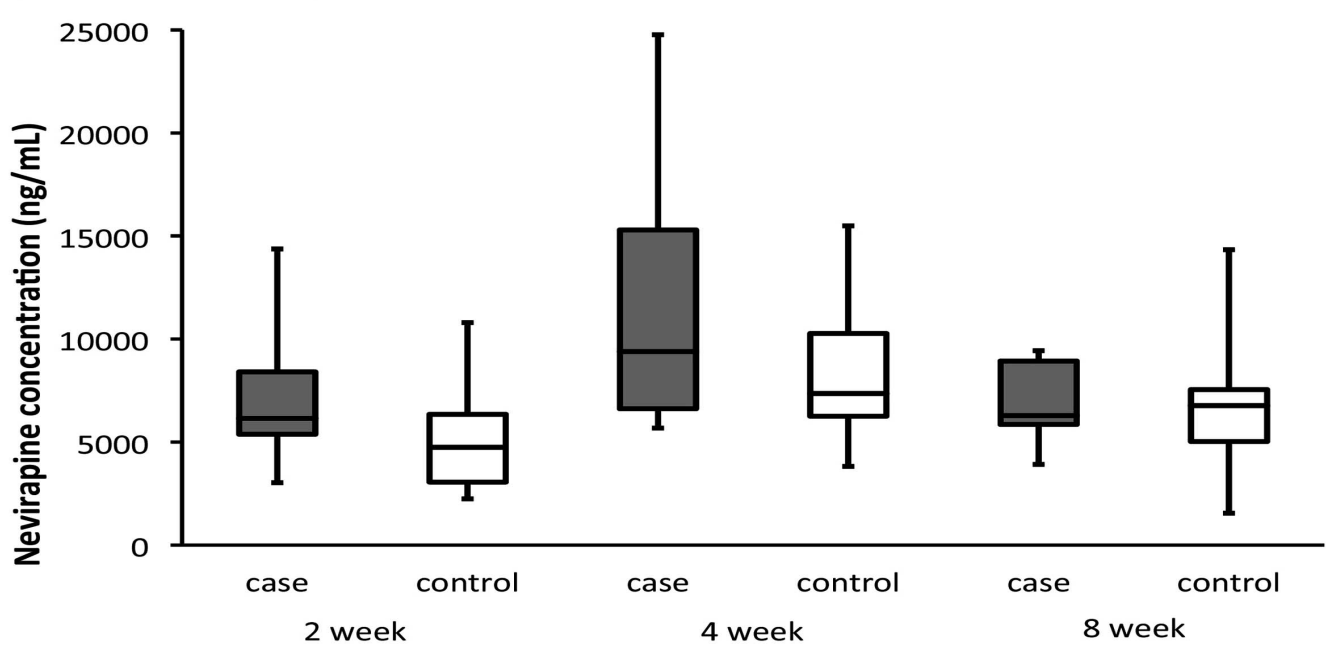

Visit week

Fig. (1). Nevirapine Concentrations at 2, 4, and 8 Weeks after Starting Treatment, Bangkok, Thailand, 2005-2007.

Box-whisker plots (center line $=$ median, top and bottom of box $=$ interquartile range, ends of vertical line $=$ minimum and maximum values) of pre-dose and post-dose plasma nevirapine concentrations at 2, 4, and 8 weeks after starting treatment for women with hepatotoxicity or rash (cases) and women without hepatotoxicity or rash (controls) during the first 24 weeks of nevirapine-based antiretroviral therapy. Participants received nevirapine $200 \mathrm{mg}$ once daily for the first 2 weeks, then $200 \mathrm{mg}$ twice daily.

\begin{tabular}{|c|c|c|c|c|c|c|c|c|c|c|}
\hline & \multicolumn{9}{|c|}{ Pre-Dose } & \multicolumn{4}{c|}{ Post-Dose } \\
\hline & \multicolumn{2}{|c|}{ Case } & \multicolumn{2}{c|}{ Control } & p-Value & \multicolumn{3}{c|}{ Case } & \multicolumn{3}{c|}{ Control p-Value } \\
\hline \hline Week & $\mathrm{n}$ & $\mathrm{NVP}$ & $\mathrm{n}$ & $\mathrm{NVP}$ & & $\mathrm{n}$ & $\mathrm{NVP}$ & $\mathrm{n}$ & $\mathrm{NVP}$ & \\
\hline 2 & 24 & 3,528 & 30 & 3,150 & 0.5 & 21 & 6,150 & 20 & 4,746 & 0.02 \\
\hline 4 & 15 & 5,995 & 31 & 5,703 & - & 17 & 9,393 & 20 & 7,351 & - \\
\hline 8 & 9 & 6,078 & 27 & 4,363 & - & 8 & 6,286 & 22 & 6,766 & - \\
\hline
\end{tabular}

$\mathrm{NVP}=$ median nevirapine concentration $(\mathrm{ng} / \mathrm{mL})$

p-value is by Wilcoxon test comparing nevirapine concentration for cases versus controls at week 2 . We present the raw values of concentrations at weeks 4 and 8 , without statistical comparisons, for visual inspection.

maintaining virologic control. Viral load was available at week 24 for 98 women in this analysis who continued on NNRTI-based ART (10 women were changed to a protease inhibitor or dropped out of the study). Viral load was $<400$
copies/mL for $29(100 \%)$ of 29 women who ever had a predose or post-dose nevirapine concentration $<3,000 \mathrm{ng} / \mathrm{mL}$ and for $64(93 \%)$ of 69 women who never had a pre-dose or post-dose nevirapine concentration $<3,000 \mathrm{ng} / \mathrm{mL}(\mathrm{p}=0.3)$. 

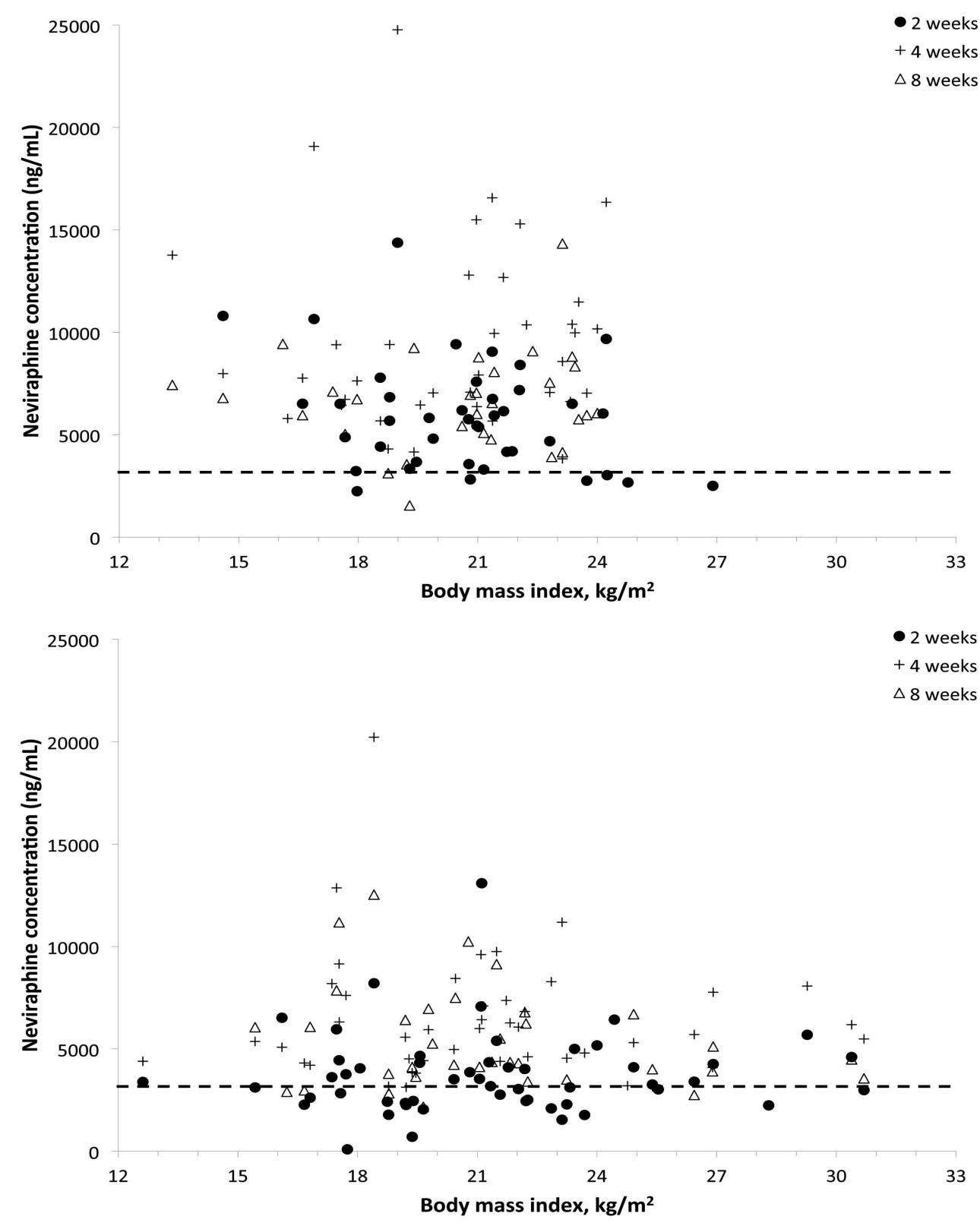

Fig. (2). Nevirapine Concentrations Plotted against Body-mass Index at 2, 4, and 8 Weeks after Starting Treatment, Bangkok, Thailand, 2005-2007. Nevirapine post-dose (2a) and pre-dose (2b) concentrations at week 2 (closed circle), week 4 (plus sign), and week 8 (open triangle) after starting treatment. There was a marginally significant relationship between body-mass index and nevirapine concentration for post-dose at week 2 (Pearson's $r=-0.31, p=0.051)$, but not for pre-dose at week $2(r=-0.013, p=0.92)$. We present the raw values of concentrations at weeks 4 and 8 for visual inspection. The horizontal dashed line is drawn at a concentration of $3,000 \mathrm{ng} / \mathrm{mL}$, the usual minimum target trough plasma concentration for nevirapine. There was one additional woman with a body-mass index of $37.9 \mathrm{~kg} / \mathrm{m}^{2}$ who had pre-dose nevirapine concentrations at week 2 of $2,317 \mathrm{ng} / \mathrm{mL}$, at week 4 of $6,226 \mathrm{ng} / \mathrm{mL}$, and at week 8 of $5,245 \mathrm{ng} / \mathrm{mL}$; these outlier values were excluded to optimize clarity of the figure. All women with specimens that could be characterized as pre-dose or post-dose measurements are represented.

\section{DISCUSSION}

Among Thai women, rash or hepatotoxicity during the first 24 weeks of NNRTI-based ART was associated with higher post-dose, but not pre-dose, plasma nevirapine concentrations at week 2 while taking nevirapine once daily. There was a marginal association of lower body-mass index with higher post-dose nevirapine concentrations at week 2 , although this finding must be interpreted cautiously since the body-mass index only explained approximately $9 \%$ of the variation seen in nevirapine concentrations at this time point.

A higher post-dose nevirapine concentration after 2 weeks of the recommended lead-in dose of $200 \mathrm{mg}$ daily suggests that persons who will develop rash or hepatotoxicity may have elevated concentrations of nevirapine soon after starting nevirapine. However, an elevated post-dose concentration at week 2 alone does not appear to be sufficient to explain these reactions, since many 
Table 2. Nevirapine Pre-Dose and Post-Dose Concentrations 2, 4, and 8 Weeks after Starting Treatment, Bangkok, Thailand, 2005-2007

\begin{tabular}{|c|c|c|c|}
\hline \multirow{2}{*}{ Nevirapine Concentration (ng/mL) } & \multicolumn{2}{|c|}{ Weeks After Starting Nevirapine-Based Antiretroviral Therapy } \\
\cline { 2 - 4 } & $\begin{array}{c}\text { Week 2 } \\
\text { n (\%) }\end{array}$ & $\begin{array}{c}\text { Week 4 } \\
\text { n (\%) }\end{array}$ & $\begin{array}{c}\text { Week 8 } \\
\text { n (\%) }\end{array}$ \\
\hline \hline Pre-Dose & $\mathbf{5 4}$ measurements & $\mathbf{4 6}$ measurements & 36 measurements \\
\hline$<3,000$ & $21(39)$ & $0(0)$ & $5(14)$ \\
\hline $3,000-5,999$ & $28(52)$ & $25(54)$ & $18(50)$ \\
\hline $6,000-8,999$ & $4(7)$ & $15(33)$ & $9(25)$ \\
\hline$\geq 9,000$ & $1(2)$ & $6(13)$ & $4(11)$ \\
\hline Post-Dose & $\mathbf{4 1}$ measurements & $\mathbf{3 7}$ measurements & 30 measurements \\
\hline$<3,000$ & $5(12)$ & $0(0)$ & $1(3)$ \\
\hline $3,000-5,999$ & $18(44)$ & $6(16)$ & $11(37)$ \\
\hline $6,000-8,999$ & $12(29)$ & $17(46)$ & $14(47)$ \\
\hline$\geq 9,000$ & $6(15)$ & $4(13)$ \\
\hline
\end{tabular}

Pre-dose and post-dose nevirapine concentrations presented in ranges of concentrations from below the targeted minimum concentration $(<3,000$ ng/mL $)$ to very high concentration $(\geq 9,000 \mathrm{ng} / \mathrm{mL}$ ). Participants received nevirapine $200 \mathrm{mg}$ once daily for the first 2 weeks, then $200 \mathrm{mg}$ twice daily thereafter. All women with specimens that could be characterized as pre-dose or post-dose measurements are represented.

patients had post-dose concentrations $>9,000 \mathrm{ng} / \mathrm{mL}$ at either weeks 2,4 , or 8 , yet did not develop rash or hepatotoxicity. We observed extremely wide inter-patient variability in nevirapine concentrations at weeks 2,4 , and 8 . At week 2 , following the once daily $200 \mathrm{mg}$ lead-in dose, nevirapine concentrations were $\sim 30-40 \%$ lower than those at weeks 4 and 8 after the dose had been escalated to $200 \mathrm{mg}$ twice daily. It is reassuring that a nevirapine concentration $<3,000$ $\mathrm{ng} / \mathrm{mL}$ measured at week 2 was not associated with virologic failure while on NNRTI-based ART at week 24

Nevirapine-associated rash, hepatotoxicity, and rashassociated hepatotoxicity typically occur in the first few weeks to months of therapy; patients who tolerate nevirapine for the first few months will likely tolerate it indefinitely [2]. Some studies have supported an association between risk for hepatotoxicity and CD4 cell count $\geq 250$ cells $/ \mu \mathrm{L}$ in women $[26,27]$ but others have not [14,28]. We have previously demonstrated from the parent study of this sub-study that among women taking nevirapine-based ART, severe hepatotoxicity and rash-associated hepatotoxicity were predicted by abnormal baseline ALT or AST results but not by a CD4 count $\geq 250$ cells/ $\mu \mathrm{L}$ [14]. Co-infection with viral hepatitis $\mathrm{B}$ or $\mathrm{C}$ has also been associated with hepatotoxicity from antiretroviral therapy in some [29,30] but not all studies [30,31].

We did not record the precise time of ingestion of the antiretroviral drug in relation to the time the blood sample was taken. We characterized the nevirapine concentrations as either pre-dose or post-dose based on the concentration of stavudine and lamivudine from the same sample. The rationale for doing so was strengthened by the fact that nevirapine, stavudine, and lamivudine were taken simultaneously in the same fixed-dose combination tablet and the three drugs have relatively different pharmacokinetic properties. Our sample size for any one comparison was smaller than if we had a priori designed the study to collect all pre-dose samples. This limited our ability to detect relatively small differences in nevirapine concentrations between cases and controls. Likewise, our comparisons for other co-factors associated with nevirapine concentrations (e.g., concomitant fluconazole use, hepatitis B surface antigenemia) were limited by small numbers for comparisons. We had to design our analysis to account for uncontrolled timing of ingestion that may have resulted in women with varying predose or post-dose nevirapine concentrations, and for cases who changed from nevirapine to another drug after a reaction resulting in decreasing numbers of observations over time. This limitation reduced our sample size for comparisons and limited our ability to detect an association with rash or hepatotoxicity with smaller differences in pre-dose nevirapine concentrations. We did not conduct similar drug concentration testing among the Kenyan and Zambian women enrolled in this study, therefore we have no data on those women using this study design. Lastly, we did not test for other possible chemical causes of hepatitis such as aflatoxin exposure.

In conclusion, we could not demonstrate definitively that nevirapine concentrations after a two week lead-in dose of 200 $\mathrm{mg}$ daily are associated with rash or hepatotoxicity among Thai women. Many patients who tolerated nevirapine well for 24 weeks had week 2 concentrations that were much higher than some of those who developed rash or hepatotoxicity. It is unlikely that therapeutic drug monitoring after the first two weeks of therapy will substantively improve identification of patients at risk for these nevirapine-associated adverse events.

\section{ROLES OF AUTHORS}

Study Concept and Design: Drs. Ratanasuwan, Jariyasethpong, Anekthananon, Intalapaporn were the primary Thai investigators, Drs. Raengsakulrach, Peters, McNicholl, McConnell, and Weidle were the primary CDC Investigators responsible for design of the study.

Laboratory methods and interpretation of laboratory results: Dr. Kongpatanakul, Ms. Pongnarin, Ms. Wasinrapee, Dr. Raengsakulrach, Dr. McNicholl. 
Statistical Analysis: Ms. Chantharojwong, Dr. Ratanasuwan, Dr. Peters, Dr. McConnell and Dr. Weidle led the statistical analysis and interpretation.

Writing: Drs. Ratanasuwan, Peters and Weidle wrote the main draft of the manuscript. All co-authors reviewed, critiqued, and provided written concurrence with the final draft of the manuscript.

\section{CONFLICT OF INTEREST}

The authors confirm that this article content has no conflict of interest.

\section{ACKNOWLEDGEMENTS}

This work was supported by the U.S. CDC through purchase orders \#Bangkok-07-M-0424 to the Department of Preventive and Social Medicine, Faculty of Medicine, Siriraj Hospital, Mahidol University and \#Bangkok-07-M-0425 to Rajavithi Hospital.

This publication was made possible by support from the President's Emergency Plan for AIDS Relief (PEPFAR) from the Department of Health and Human Services (DHHS)/Centers for Disease Control and Prevention (CDC), Global AIDS Program and from the Division of HIV/AIDS Prevention, CDC. The findings and conclusions in this report are those of the authors and do not necessarily represent the views of the CDC.

\section{REFERENCES}

[1] Ananworanich J, Moor Z, Siangphoe U, et al. Incidence and risk factors for rash in Thai patients randomized to regimens with nevirapine, efavirenz or both drugs. AIDS 2005; 19: 185-92

[2] Zhou J, Phanupak P, Kiertiburanakul S, Ditangco R, Kamarulzaman A, Pujary S. Highly active antiretroviral treatment containing efavirenz or nevirapine and related toxicity in the TREAT Asia HIV Observational Database. J Acquir Immune Defic Syndr 2006; 43: 501-3.

[3] Pollard RB, Robinson P, Dransfield K. Safety profile of nevirapine, a nonnucleoside reverse transcriptase inhibitor for the treatment of human immunodeficiency virus infection. Clin Ther 1998; 20: 1071-92.

[4] Havlir D, Cheeseman SH, McLaughlin M, et al. High-dose nevirapine: safety, pharmacokinetics, and antiviral effect in patients with human immunodeficiency virus infection. J Infect Dis 1995; 171: 537-45.

[5] Cheeseman SH, Hattox SE, McLaughlin MM, et al. Pharmacokinetics of nevirapine: initial single-rising-dose study in humans. Antimicrob Agents Chemother1993; 37: 178-82.

[6] la Porte CJL, Back DB, Blaschke T, et al. Updated guideline to perform therapeutic drug monitoring for antiretroviral agents. Rev Antivir Ther 2006; 3: 4-14.

[7] de Maat MM, ter Heine R, Mulder JW, et al. Incidence and risk factors for nevirapine-associated rash. Eur J Clin Pharmacol 2003; 59: 457-62.

[8] De Requena DG, Jimenez-Nacher I, Soriano V. Changes in nevirapine plasma concentrations over time and its relationship with liver enzyme elevations. AIDS Res Hum Retroviruses 2005; 21: 555-9.

[9] Almond LM, Boffito M, Hoggard PG, et al. The relationship between nevirapine plasma concentrations and abnormal liver function tests. AIDS Res Hum Retroviruses 2004; 20: 716-22.

[10] Kappelhoff BS, van Leth F, MacGregor TR, Lange J, Beijnen JH, Huitema AD. Nevirapine and efavirenz pharmacokinetics and covariate analysis in the 2NN study. Antivir Ther 2005; 10: 145-55.

[11] Kappelhoff BS, van Leth F, Robinson PA, et al. Are adverse events of nevirapine and efavirenz related to plasma concentrations? Antivir Ther 2005; 10: 489-98.
[12] Autar RS, Wit FW, Sankote J, et al. Nevirapine plasma concentrations and concomitant use of rifampin in patients coinfected with HIV-1 and tuberculosis. Antivir Ther 2005; 10: 937-43.

[13] Stringer JSA, McConnell MS, Kiarie J, et al. Effectiveness of Nonnucleoside reverse-transcriptase inhibitor-based antiretroviral therapy in women previously exposed to a single intrapartum dose of nevirapine: a multi-country, prospective cohort study. PLoS Med 2010; 7: 1-13.

[14] Peters PJ, Stringer JSA, McConnell MS, et al. Nevirapine-associated hepatotoxicity was not predicted by CD4 cell count $\geq 250$ cells $/ \mu \mathrm{L}$ among women in Zambia, Thailand, and Kenya. HIV Med 2010; 11: 650-60.

[15] NIH Division of AIDS. Division of AIDS table for grading the severity of adult and pediatric adverse events. 2004. Available at: http: //www3.niaid.nih.gov/LabsAndResources/resources/DAIDSClinRsrch/ PDF/DAIDSAEGradingTable.pdf. [Last Updated: December 2004, Accessed: 5 November 2009]

[16] Zerit [package insert]. Princeton NJ: Bristol-Myers Squibb; 2009.

[17] Epivir [package insert]. Research Triangle Park, NC: Glaxo Smith Kline 2009.

[18] Lea AP, Faulds D. Stavudine: a review of its pharmacodynamic and pharmacokinetic roperties and clinical potential in HIV infection. Drugs 1996; 51: 846-64.

[19] vanPraag RME, van Weert ECM, van Heeswijk RPG, et al. Stable concentrations of zidovudine, stavudine, lamivudine, abacavir, and nevirapine in serum and cerebrospinal fluid during 2 years of therapy. Antimicrob Agents Chemother 2002; 46: 896-9.

[20] Horton CM, Dudley MN, Kaul S, et al. Population pharmacokinetics of stavudine $(\mathrm{d} 4 \mathrm{~T})$ in patients with AIDS or advanced AIDS-related complex. Antimicrob Agents Chemother 1995; 39: 2309-15.

[21] Rana KZ, Dudley MN. Clinical pharmacokinetics of stavudine. Clin Pharmacokin 1997; 33: 276-84.

[22] Yuen GJ, Lou Y, Bumgarner NF, et al. Equivalent steady-state pharmacokinetics of lamivudine in plasma and lamivudine triphosphate within cells following administration of lamivudine at 300 milligrams once daily and 150 milligrams twice daily. Antimicrob Agents Chemother 2004; 48: 176-82.

[23] Bruno R, Regazzi MB, Ciappina V, et al. Comparison of the plasma pharmacokinetics of lamivudine during twice and once daily administration in patients with HIV. Clin Pharmacokin 2001; 40: 695700 .

[24] Sabo JP, Lamson MJ, Gerhard L, Yong CL, MacGregro TR. Pharmacokinetics of nevirapine and lamivudine in patients with HIV-1 infection. AAPS Pharm Sci 2002; 2: 1-7.

[25] Viramune [package insert]. Ridgefield, CT: Boehringer-Ingelheim Pharmaceuticals Corp 2008.

[26] Sanne I, Mommeja-Marin H, Hinkle J, et al. Severe hepatotoxicity associated with nevirapine use in HIV-infected subjects. J Infect Dis 2005; 191: 825-82.

[27] Baylor MS, Johann-Liang R. Hepatotoxicity associated with nevirapine use. J Acquir Immune Defic Syndr 2004; 35(5): 538-9.

[28] Coffie PA, Tonwe-Gold B, Tanon AK, et al. Incidence and risk factors of severe adverse events with nevirapine-based antiretroviral therapy in HIV-infected women. MTCT-Plus program, Abidjan, Cote d'Ivoire. BMC Infect Dis 2010; 10: 188.

[29] Stern JO, Robinson PA, Love J, Lanes S, Imperiale MS, Mayers DL. A comprehensive hepatic safety analysis of nevirapine in different populations of HIV infected patients. J Acquir Immune Defic Syndr 2003; 34(Suppl 1): S21-33.

[30] Sulkowski MS, Thomas DL, Mehta SH, Chaisson RE, Moore RD. Hepatotoxicity associated with nevirapine or efavirenz-containing antiretroviral therapy: role of hepatitis C and B infections. Hepatology 2002; 35: 182-9.

[31] Weidle PJ, Moore D, Mermin J, et al. Liver enzymes improve over 24 months of first-line non-nucleoside reverse transcriptase inhibitor-based therapy in rural Uganda. AIDS Patient Care and STDs 2008; 22(10): 19.

This is an open access article licensed under the terms of the Creative Commons Attribution Non-Commercial License (http://creativecommons.org/licenses/by-nc/ 3.0/) which permits unrestricted, non-commercial use, distribution and reproduction in any medium, provided the work is properly cited. 